\title{
PREVENTION AND MANAGEMENT OF RELAPSE OF ACUTE LEUKEMIA AND MYELODYSPLASTIC SYNDROME AFTER ALLOGENEIC HEMATOPOIETIC CELL TRANSPLANTATION IN PEDIATRIC PATIENTS
}

\author{
Rita de Cássia Barbosa Tavares', Polliany Roberta Dorini Pelegrina² \\ 1. Bone Marrow Transplant Center- CEMO, Instituto Nacional de Câncer, Rio de Janeiro, RJ, Brazil. Email: ritacbt@gmail.com \\ 2. Bone Marrow Transplant Unit, Hospital Pequeno Príncipe, Curitiba-PR, Brazil. E-mail:polliany.pelegrina@gmail.com \\ Correspondence to: ritacbt@gmail.com
}

\begin{abstract}
SUMMARY
The best way to manage acute leukemia relapse after $\mathrm{HCT}$ is to prevent it, buying time for GVL with immunomodulation and, if no GVHD between days +60 and +90 , prophylactic DLI can be indicate for very high or high risk patients. Short-term low dose of cyclosporine or methotrexate can add safety to pro-DLI, particularly after mismatched or unrelated transplantation. Maintenance with imatinib or dastinib, recommended for Ph-positive ALL, with sorafenib, for FLT3-ITD AML, or azacitidine, for myelodysplastic syndrome patients, can be effective in reducing relapse rates. However, target agent maintenance can add toxicity, depends on patient adherence and demands physician experience to know when is safe to start, how adjust the dose according individual tolerance after transplant and to detect undesirable drug interactions. The second step to avoid hematological relapse is preemptive approach guided by measurable residual disease or mixed chimerism. In patients off immunosuppression, chemotherapy followed by DLI is a useful strategy, and if no response, interferon alpha can be associated to enhance GVL. Target-specific agents can be start at this point either. After relapse, antigen-directed therapy with blinatumumab for CD19 ALL, inotuzumab for CD22 ALL are excellent options to induce MRD negativity and facilitate HCT. Disadvantages of new immunotherapies are: high incidence of VOD with inotuzumab and gemtuzumab; lower response in patients with high leukemia burden or concurrent extramedullary relapse; necessity of consolidation with HCT after a bridging therapy with BiTE and probably with CAR-T cell therapy also. It is important to realize that if remission after chemotherapy is associated with the development of GVHD, then there may be limited benefit (and possibly harm) in consolidating with any kind of cellular therapy. However, for patients who achieved remission without GVHD, either DLI or second transplant can be recommend. Further studies are necessary to determine at which point each strategy might yield the best results.
\end{abstract}

Keywords: Acute leukemia, myelodysplastic syndrome, relapse, allogeneic hematopoietic cell transplantation 


\section{INTRODUCTION}

Advances in leukemia biology knowledge, supportive care and combined treatment approaches added to the recent progress in haploidentical transplantation, which made possible a significant increase of donor availability for allogeneic hematopoietic cell transplantation (allo-HCT), had resulted in cures for approximately $85 \%$ of children with lymphoblastic acute leukemia (ALL) and 70\% for those with myeloid acute leukemia (AML) or with myelodysplastic syndrome (MDS). ${ }^{1-2}$ Allo-HCT is considered an established treatment for patients with high risk hematological malignancies. ${ }^{3}$ The 3-year overall survival (OS) for children with ALL or AML varies, according disease phase, from $76-60 \%$ for early and intermediate to $50 \%-30 \%$ for advanced phase, respectively, with comparable outcomes after matched sibling (MSD) or matched unrelated (MUD) $\mathrm{HCT}^{4}$ Relapse incidence (RI) following transplantation varies from 13 to $47 \%$, depending on patient, disease and transplant features, while the incidence of CNS relapse, the most common site of extramedullary relapse, varies from 3.9 to $9.4 \%$ for patients without or with prior CNS disease, respectively. 5

In Brazil, two recent retrospective multicenter studies evaluated outcomes in pediatric patients and observed lower OS rates compared to higher-income countries. Tavares and cols. ${ }^{7}$ reported acceptable 3-year relapse rates of 23\% (30/130) for ALL and 18\% $(15 / 82)$ for AML/MDS patients transplanted with unrelated $\mathrm{HCT}$, which were similar among donor type groups: matched (26\%), mismatched (21\%) and umbilical cord blood (13\%) $(P=.18)$. A higher relapse incidence $(43 \%)$ was published by de Melo Rodrigues and cols. ${ }^{8}$ when they analyzed 114 AML patients that received MSD (49), MUD (59) and haploidentical (6) HCT. The 4-year progression-free survival (PFS) for all cohort was $40 \%$. Relapse occurred at a median of 122 days. After relapse, 12 patients received a second HCT, and four received donor lymphocyte infusion (DLI). Of the patients who experienced relapse, only six (12.2\%) survived. The authors observed a significant association $(P<0.0001)$ for 4-year PFS, with worse outcomes recorded for patients in third or subsequent complete remission (CR) (HR 6.71) and for those with active disease (HR 3.08) at transplant.

The mainly risk factors for relapse in children with acute leukemia after HCT are advanced disease phase at transplantation, pre and post-HCT positive measureable residual disease (MRD) and absence of GVHD. Besides that, presence of high risk cytogenetics and molecular alterations at diagnosis, such as: BCR-ABL mutations; MLLT4-KMT2A; IKZF1 e 2; ETV6/
RUNX1-like; iAMP21; TCF3/HFL; FLT3-ITD, monosomy 7, complex karyotype and TP53 mutations, among others, increase disease recurrence after HCT.

Graft-versus-leukemia effect (GVL) and myeloablative conditioning are crucial tools in prevention of leukemia relapse after allo-HCT. The GVL takes time to happen and, meanwhile, host leukemic cells persistence, which escaped the cytotoxicity of conditioning, can induce leukemia recurrence. Other mechanisms, such as: chemotherapy or graft insufficiency, inadequate responses by effector cells, immune mechanisms resistance induced by ALL blasts, migration of leukemic cells to sanctuaries protected from immune attack, inhibition of antitumor response by the tolerance conferred by immune microenvironment components (mesenchymal stem cells and T, B, NK regulatory cells), also contribute to relapse. ${ }^{9,10}$ Standard recommendations to prevent relapse after transplant include: 1) improve disease control before HCT; 2) increase graft GVL potency by optimizing donor selection, conditioning, graftversus-host disease (GVHD) prophylaxis; 3) keep disease under control until the GVL occurs, which can be achieved through target agents maintenance, immunosuppression (IS) modulation and/or prophylactic DLI; 4) monitor and act immediately if detect impending relapse. Advances in immunomodulatory interventions and maintenance approaches, with tyrosine kinase inhibitors (TKI) or hypomethylating agents (HMAs), have benefit selected patients..$^{8-13}$ Pulsipher et al reported ${ }^{9}$, in a multicenter prospective study, risk factors and timing of relapse after allogeneic transplantation in a pediatric population diagnosed with ALL. They concluded that there is a window between day +55 and day +100 to 200 when most high-risk patients have not relapsed yet and that this population could benefit from measures to avoid relapse at that time.

\section{TKI MAINTENANCE POST-HCT}

Relapse after HCT for Philadelphia chromosome-positive $(\mathrm{Ph}+) \mathrm{ALL}$ remains a significant challenge. Since the incorporation of TKI in first line treatment protocols, its maintenance post-HCT was indicate. Chen ${ }^{14}$ and cols. compared outcomes in pediatric patients, 62 with imatinib versus 20 without maintenance post-HCT. Multivariate analysis identified maintenance therapy post-HCT with imatinib as an independent prognostic factor for DFS ( $p=.0001$, $H R=4.8)$ and $O S(p=.0001, H R=6.2)$. According to EsPhALL 2010 protocol, daily imatinib should start at $200 \mathrm{mg} / \mathrm{m}^{2}$ by day +56 , provided that satisfactory counts with stable neutrophil engraftment (plate- 
let $>50 \times 10^{\circ}$ cells $/ \mathrm{L}, \mathrm{WBC}>1.5 \times 10^{\circ}$ cells $/ \mathrm{L}$, and neutrophils $>0.5 \times 10^{9}$ cells $/ L$ for at least 15 days) were achieved. If well tolerated, daily dose should be increase to $300 \mathrm{mg} / \mathrm{m}^{2}$ until 12 months. $^{15}$

The Acute Leukemia Working Party of the EBMT ${ }^{16}$ published a state position on the use of TKI to prevent relapse after allo-HCT for patients with Philadelphia (Ph) positive ALL. The authors made important recommendations to guide dose reductions according TKI toxicities, disease monitoring, maintenance duration and specific indications such as the choice of dasatinib maintenance for patients with previous CNS involvement. They advised that for patients transplanted in CR1 and continuous MRD negativity maintenance shoud last 12 months, but those transplanted in CR2 or a later remission should prolong TKI use indefinitely, unless precluded by poor tolerability or safety concerns. They concluded that the available data are insufficient to determine the better tolerated TKI in post-HCT setting. The choice has to be personalized according comorbidities and transplant complications. Moreover, patients with GVHD or transplant-related morbidities and undetectable MRD post-HCT may use TKI prophylactically or, alternatively, only after the detection of MRD (preemptive strategy). A recent systematic review performed by Warrich and cols. ${ }^{17}$, analyzed comparatively survival outcomes with first and second-generation TKI maintenance on post-HCT setting in $\mathrm{Ph}+$ ALL adult patients. They showed that the use of either imatinib or dastinib after transplant for patients in CR1 improved OS when given as a prophylactic or preemptive regimen. Limited data suggest that second-generation TKI (i.e., dasatinib) have a better OS, especially in patients with MRD-positive status. Imatinib did not improve OS in patients who were $>$ CR1 at the time of HCT. The evaluation of survival benefit with newer generation TKI and their efficacy in patients transplanted in > CR1 needs further study in large randomized clinical trials. Evaluation of the use of dasatinib for maintenance post-HCT in $\mathrm{Ph}+$ ALL children is an unmet need. Watanabe and cols. ${ }^{18}$ reported prolonged molecular remission with dasatinib pre and post-HCT in a 10-year boy with imatinib resistant $\mathrm{Ph}+\mathrm{ALL}$ transplanted in molecular remission. Dasatinib use started on day +102 at $20 \mathrm{mg} /$ $\mathrm{m}^{2} /$ day and gradually increased to $50 \mathrm{mg} / \mathrm{m}^{2} /$ day. After 2-year-lasting molecular remission, dasatinib was suspended, and the patient was still in remission at day +905 MRD analysis. Recently, Shen and cols. ${ }^{19}$ conducted a phase 3 RCT study with 189 children to compare the efficacy of dasatinib versus imatinib in pre-HCT setting. Dasatinib $\left(80 \mathrm{mg} / \mathrm{m}^{2} /\right.$ day) was more effective than imatinib $\left(300 \mathrm{mg} / \mathrm{m}^{2} /\right.$ day) in the treatment of children with $\mathrm{Ph}+\mathrm{ALL}$. Dasatinib therapy provided excellent control of CNS leukemia without the use of prophylactic cranial irradiation. These evidences justify the use of dasatinib as an option for maintenance post-HCT in pediatric patients, however routinely hematological counts and cytomegalovirus PCR screening are necessary for adequate dose adjustment and to prevent hemorrhagic colitis dasatinib induced, associated or not with CMV. ${ }^{20}$

FLT3-Internal Tandem duplication (ITD)-mutated AML is associated with poor outcomes. Allo-HCT can improve cure rates in children and adults, however around $35 \%$ of patients relapse. Maintenance postHCT with sorafenib, an oral TKI with activity against FLT3, c-KIT, PDGF, VEGF and Raf, is a currently recommendation for FLT3-ITD-mutated AML patients, based on significant improvements in DFS, OS and a marked $65 \%$ reduced risk for relapse with two years of TKI therapy. ${ }^{21}$ Tarlock and cols. ${ }^{22}$ reported the response of 15 pediatric patients with FLT3-ITD-mutated AML to prophylactic (6) or therapeutic (9) sorafenib, which started around day +100 and was suspended at 18 months post-HCT. Initial median dose was $150 \mathrm{mg} / \mathrm{m}^{2} /$ day. Overall, $73 \%$ of patients experienced significant toxicities, although sorafenib did not appear to exacerbate graft versus host disease in this study. Among patients who experienced toxicity, $7 / 11$ (64\%) received doses $\geq 200 \mathrm{mg} / \mathrm{m}^{2} /$ day, which was later determined to be the maximum tolerated dose of sorafenib for pediatric leukemia. The authors observed a relevant efficacy of sorafenib in patients with MRD positive, since all patients treated for MRD immediately prior to transplant or with emergence of MRD after transplant were alive, in complete remission, at a median of 48 months postHCT. Thus, for patients not receiving prophylaxis, administration of TKI at the first detection of MRD is recommend. Patients who achieve MRD-negative response by molecular detection methods may not require second HCT. More recently, Xuan and cols. ${ }^{23}$ retrospectively evaluated sorafenib therapy (dose range, 200-800 mg daily) in 144 FLT3-ITD-mutated AML transplanted patients, with ages between 14 and 57 years. The study multivariate analysis showed that, compared with control group, the utilization of sorafenib before transplantation, as maintenance after $\mathrm{HCT}$, and their combined application were significantly protective factors for a lower relapse rate (HRs: $0.44,0.43$ and 0.17 , respectively) and for a longer LFS (HRs: $0.32,0.34$, and 0.19 , respectively).

Sorafenib maintenance post-HCT (group A) was compared with prophylactic DLI (group B) and with patients without prophylactic intervention (group C) by Shi and cols. ${ }^{24}$ in a retrospective study with 68 
FLT3-ITD positive AML patients who received MSD $(n=21), \operatorname{MUD}(n=7)$ and haploidentical $(n=40)$ transplantation. The overall range of age was $12-62$ years. When interventions started, all patients who received $\mathrm{pDLI}$ or sorafenib had complete chimerism, were negative for MRD and FLT3- ITD mutation and had no active GVHD. Sorafenib maintenance started at a median of 83 days post-HCT and last for a median of 238 days. Group B received DLI only once at a median of 102 days post-HCT. The median of $\mathrm{CD}^{+}$ cell dose was $3.4 \times 10^{7} / \mathrm{kg}$. The 2-year OS, LFS, and CIR were $95.8 \%, 95.8 \%$, and $4.2 \%$, respectively, for group A; $75 \%, 66.7 \%$, and $25.0 \%$, respectively, for group $B$; and $67.0 \%, 60.9 \%$, and $33.4 \%$, respectively, for group C. Overall survival and LFS were significantly higher in sorafenib group. The grade II-IV aGVHD incidence was significantly higher after DLI than in sorafenib group (46.3 vs $8.7 \%, P<0.001$ ), but there was no significant difference between these groups in CGVHD incidence.

\section{DNA HYPOMETHYLATING AGENTS (HMAS) POST-HCT}

The most common non-targeted pharmacologic approach to treatment and prevention of relapse after HCT for AML and MDS has been HMAs (azacitidine and decitabine). Their mechanism of action post-HCT is uncertain, but they can induce allogeneic $C D 8^{+} T$ cell response by enhancing the expression of epigenetically silenced tumor-associated antigens. HMAs may also induce the GVL response through increased expression of tumor antigens. ${ }^{25}$ Prophylactic azacitidine (Aza) post-HCT was first evaluated in a phase I study of 45 adults heavily treated previously, which established an optimal dosing schedule for maintenance to be $32 \mathrm{mg} / \mathrm{m}^{2} \mathrm{IV} \times 4$ cycles and resulted in a 1 -year OS rate of $77 \%$. Reversible thrombocytopenia was the dose limiting toxicity. ${ }^{26}$ Unfortunately, this study extension to a phase III randomized controlled trial (RCT), failed to show significant differences for OS and DFS between Aza and control groups ( $p=$ .85 and $p=.14$ ), respectively. ${ }^{27}$ However, pediatric case series ${ }^{28-29}$ reported low incidence of relapse with prophylactic low-dose Aza ( 32 to $36 \mathrm{mg} / \mathrm{m}^{2}$ ) as maintenance post-HCT. Despite the limitations of small numbers, a potential benefit in disease control of this approach warrants further investigation.

Recently, Hurchart and cols. ${ }^{30}$ reported the results of a protocol combining Aza maintenance with prophylactic DLI (pro-DLI) performed in 10 high-risk AML pediatric patients. Aza started on Day +60 at 36 $\mathrm{mg} / \mathrm{m}^{2}$ for a 5-day monthly course from day +90 , for 6 cycles. The dose was reduced to $24 \mathrm{mg} / \mathrm{m} 2$ if grade
3 or 4 of hematologic toxicity or increase of bilirubin $>3 x$ upper limit of normal persistent for $>2$ weeks. Escalated pro-DLI started after Day +120 in patients off immunosuppression for at least 1 month, repeated every 6 weeks and limited to three doses. Patients with previous grades III-IV aGVHD were excluded. Initial CD3/kg doses were $10^{6}$ for MSD, $0.5 \times 10^{6}$ for MUD and $0.5 \times 10^{5}$ for MMUD and haploidentical HCT. The increase of subsequent doses was by 0.5 log each. Nine patients (90\%) remained in CR with median follow up of 17 months. These preliminary results suggest that post-HCT maintenance therapy with Aza and pro-DLI in pediatric setting is feasible, safe, and may contribute to improved event free survival.

\section{PROPHYLACTIC DONOR LYMPHOCYTE INFUSION}

Although the efficacy of therapeutic DLI in relapsed acute leukemia may be suboptimal, pre-emptive or, particularly, prophylactic DLI is effective approaches. However, the risk of severe acute GVHD (aGVHD) remains an obstacle to successful earlier use of DLI after HCT. To balance GVHD risk and GVL effect, the first pro-DLI CD3 ${ }^{+}$cell dose should vary between $10^{4}$ and $10^{6} / \mathrm{kg}$, according donor type, mainly if given before 6 months after $\mathrm{HCT}^{31}$ Some authors suggest that is safe and more effective to administer G-CSF-primed DLIs early after transplant, and this kind of manipulation can provide GVL effect without significant GVHD. ${ }^{32-34}$ Yan and cols. ${ }^{34}$, in a multicenter prospective study, evaluated the impact of G-CSF-mobilized peripheral blood stem cells (pro-G-DLI) followed by MRD and GVHD-guided multiple G-DLIs in preventing relapse after transplant in 100 patients (aged 6 $60 \mathrm{yrs}$.) with refractory/relapsed acute leukemia. The pro-G-DLI was at 30 days after MSD or 45 to 60 days after MUD or haploidentical transplants. Patients in CR at day+30, without GVHD and uncontrolled infection were eligible. Subsequently G-DLIs were according GVHD occurrence and MRD results (at 1, 2, $3,4.5,6,9$, and 12 months and at 6-month intervals thereafter). Patients with positive MRD received chemotherapy and G-DLI. The median dose of mononuclear cells, CD3+ cells, and CD34+ cells for each G-DLI was $10^{8} / \mathrm{kg}, 0.37 \times 10^{8} / \mathrm{kg}$ and $0.65 \times 10^{6} / \mathrm{kg}$, respectively. Before pro-G-DLI, all patients received 2.5 $\mathrm{mg} / \mathrm{kg} /$ day of cyclosporine (CsA) to prevent GVHD. After G-DLI, CsA dose and duration were adjusted according blood levels and MRD results, respectively. The 3-year CIR, DFS, and OS were 32.4\%, 50.3\%, and $51.4 \%$, respectively. The authors suggested that this prophylactic and disease guided combined intervention reduced relapse and increased survival 
post-transplant in patients with refractory/relapsed acute leukemia.

The risk of GVHD after unmanipulated DLI in the haplo-HCT/PTCy setting is comparable to DLI from an HLA-matched donor, following the recommended dose of $\mathrm{CD}^{+}$cell $/ \mathrm{kg}$ according the indication: prophylactic or preemptive $\left(10^{5}\right)$ and therapeutic $\left(10^{6}\right)$. Patients with high-risk myeloid malignancies may benefit from a pro-DLI, which ideally should be performed in clinical trials. However, manipulated haplo-DLI, such as selectively depleted or gene-modified T cells, only should be used on clinical trial setting. ${ }^{35}$ In a prospective study by Gilman et al. ${ }^{36}$, reported 34 pediatric patients that received an unmanipulated prophylactic haplo-DLI after a T-cell depleted /CD34+ selected haplo-HCT, with GVHD prophylaxis with MTX between $d+30$ and $d+42$. The intervention was safe and 2-year NRM and OS were $25 \%$ and $63 \%$, respectively. Similarly, Jaiswal et al. ${ }^{37}$, in a prospective trial, evaluated the use of prophylactic G-CSF-primed peripheral blood progenitor cell (GBPC) in the T-cell replete haplo-HCT/PTCy setting. Twenty-one patients with AML (not in remission) received up to three doses of haplo-GPBC $(d+21, d+35$ and $d+60$ ). All patients received GVHD prophylaxis post-DLI. The control group consisted on 20 patients who received routine monitoring after haplo-HCT. In DLI cohort at 18 months, CIR, PFS, and OS were 21\%; $62 \%$ and $71 \%$, respectively and results were significantly superior compared with controls. Incidence of aGvHD was $31 \%$, while incidence of chronic GvHD was $41 \%$ after GBPC infusions. NRM was equivalent between the groups.

\section{MEASUREABLE RESIDUAL DISEASE CONSIDERATIONS}

Improvements on relapse surveillance post-HCT became possible due to advances in monitoring MRD. The recommended methods for MRD surveillance are: multicolor (six to ten colors) flow cytometry (MFC); real-time PCR (for Ig and TCR rearrangements and fusion gene transcripts) and, more recently, next-generation sequencing of Ig or TCR genes (NGS - MRD). ${ }^{12}$ For ALL patients, the adequate time to access MRD is between 12 a 30 days before HCT, and those with MRD positive should receive additional treatment pre-HCT. ${ }^{38}$ This approach is not well defined for AML patients, and, unless in cases where target agent can be apply, a positive MRD must not delay the transplant, since allo-HCT provides acceptable survival rates in $A M L$, even in patients with very high risk disease."

MRD post-HCT is more important than pre $\mathrm{HCT}^{6}$, and screening at days $+30,+60,+90,+180$ and +365 is the routine adopted by most Brazilian centers. However, recent US National survey ${ }^{5}$ revealed a higher frequency of relapse detection at day $+270(11.9 \%)$ compared to day $+365(0 \%)$. MRD for ALL patients are classified according quantitative PCR or MFC results, respectively, as following: MRD negative (if undetectable); MRD low positive if $<10^{-4}$ or $0.01 \%$; MRD high positive if $>10^{-4}$ to $<10^{-3}$ or $>0.01$ to $0.1 \%$; and MRD very high positive if $\geq 10^{-3}$ or $>0.1 \%$. Bader and cols. $^{6}$ derived a risk score with an MRD cohort from Europe, North America, and Australia, using negative predictive characteristics (advanced disease status, non-total body irradiation regimen, and MRD [high, very high]) defining good, intermediate, and poor risk groups for relapse. They validated the score in a second cohort, more recent, and the 2-year CIR were $13 \%, 26 \%$, and $47 \%(p<.001)$ for the defined risk groups.

Ph-positive ALL patients should be evaluate also for the presence of $B C R-A B L$ transcripts and $A B L$ kinase domain mutations before HCT and after engraftment. The PCR monitoring of BCR-ABL rearrangement should start 4 weeks after transplant, be repeated every 6 to 8 weeks in bone marrow (BM) and monthly in peripheral blood (PB), during the first year post-HCT. ${ }^{16}$ After that, we recommend monitoring as follows: every 3 months in PB during the second year post-HCT, besides the 18-month BM analysis, every 6 months in PB until five years from transplant and annually afterwards. The detection of MRD should prompt rapid confirmatory testing in BM.

MRD sensitivity limit by MFC for AML is around $10^{-4}$ to $10^{-5}$. Adequate sample cellularity and standardized protocols to detect leukemia-associated immunophenotypes (LAIPs) is mandatory for accurate MRD results. However, reliable analysis of post-transplant MRD for AML patients requires also a high level of expertise, knowledge of regenerative bone marrow marker expression patterns, and an integrated approach of LAIP-based Different from Normal (DfN), which is crucial to identify new LAIPs due to clonal evolution and occurrence of immunophenotypic shifts in regenerative marrow after therapy. Despite that, MFC is currently the most commonly used method to determine MRD in AML patients. Molecular PCR based techniques have higher sensitivity than MFC $M R D$, depending on the specific gene and the used molecular technique. The chosen genes for the MRD assay are NPM1, RUNX1-RUNX1, CBF-MYH11, FLT3 and WT1. Although FLT3 harbors frequent recurring mutations, the internal tandem duplication (FLT3/ ITD) is highly unstable and can be gained or lost during therapy. However, FLT3/TTD negativity does 
not imply that residual leukemia cells are absent, and therefore highly sensitive techniques will be required to ensure FLT3/ITD negativity. The detection of Wilms' tumor 1 (WT1) by mutation and expression, has also been used by several centers for disease monitoring but the ELN 2018 MRD guidelines stated that WT1 expression should only be used when there is no other MRD marker available. ${ }^{39}$

A more sensitive method of MRD detection, NGS, is improving the predictive value of MRD for relapse and survival in ALL and AML patients after HCT. Thus, as soon become more widely available, NGS MRD should be incorporate into ALL and AML studies to identify patients who are at high risk for post-HCT relapse to allow timely interventions in order to improve patient outcomes.

\section{DONOR CHIMERISM CONSIDERATIONS}

Monitoring the post-HSCT dynamics or kinetics of chimerism status by serial bone marrow analysis at same points of MRD (listed above), as well as on suspicion of relapse or graft failure, is needed to monitor engraftment, disease control and to predict relapse. Intervals ranging from weekly to monthly chimerism analysis have been used in clinical trials. Particularly for pediatric leukemia patients, is recommended to follow chimerism closely, alternating blood samples with the scheduled marrow analysis, every 2 weeks until day +100 , at monthly basis until one year and yearly afterwards, to a minimum of 5 years postHSCT to monitor for secondary graft failure and as a marker of possible minimal residual disease and relapse. Analyses can be limited if complete chimerism has been reached and sustained, if not, serial analyses should be performed at short time intervals when a decreasing donor chimerism or persistent MC is detected. ${ }^{40}$

Chimerism analysis shows the donor origin hematopoietic cells percentage thus, complete chimerism (CC) is when $100 \%$ of hematopoietic cells are of donor origin; mixed chimerism (MC) when both donor and recipient hematopoietic cells are present and split chimerism when CC has been achieved in one or more cell lineages while other cell lineages still shows a mixed pattern. Low-level chimerism is when host cells are detect in a proportion $<1 \%$ of hematopoietic cells. Mixed chimerism can be classified as decreasing MC (reduction of host cells) and increasing MC (host cells increasing). The cell lineages generally used are mononuclear and granulocytic, but CD34+cells and specific-leukemia lineage (marrow sample) chimerism analysis can predict relapse more accurately. Chimerism is preferentially evaluated by amplification of short-tandem-repeats markers (STRPCR), due to its high sensitivity (nearly 100\%). It can be performed also by X/Y FISH (only applicable in sex mismatched HCT) and RT-qPCR, with $50 \%$ and $90 \%$ of sensitivity, respectively. ${ }^{40-41}$

Relapse prediction using chimerism relies on the interpretation of chimerism kinetics. A sustained MC or drop on donor chimerism early after HSCT has shown to be an independent risk factor for relapse and impaired survival after MAC, RIC or NMA conditioning, in both adults and children, independent of the underlying hematological malignancy. Chen and cols. ${ }^{42}$ showed that early achievement of CC in pediatric ALL patients after MAC transplant was associated with a longer PFS. Brolie and cols ${ }^{43}$ evaluated chimerism trends in 63 children who underwent HCT for AML or MDS. Mixed T-cell chimerism at engraftment and absence of cGVHD were associated with relapse ( $P=0.04$ and $P=0.02$, respectively). Mixed $\mathrm{T}$-cell chimerism at engraftment was predictive of relapse in patients without cGVHD $(P=0.03)$.

\section{Preemptive post-HSCT interventions based on MRD and chimerism kinetics}

Reduction or cessation of immunosuppression (IS) and/or DLI single or on escalonated doses can convert a MC to CC, thereby boosting the GVL effect. The efficacy of these strategies combined or not for mixed chimerism conversion has been confirmed in retrospective and cohort studies ${ }^{4-46}$ and by pediatric prospective trials ${ }^{47-49}$ also. Horn ${ }^{49}$ and cols. evaluated prospectively 71 pediatric AML patients and found that the rapid IS tapering with or without DLIs in patients presenting with $M C$ on 2 consecutive blood or bone marrow samples until achievement of CC could significantly improve DFS. The DLI CD3+ cells dose/kg schedule was according donor type, with first doses of $10^{5}$ to $10^{6}$, increased by $0.5 \log$ for each subsequent dose until limits of $10^{7}$ and $10^{8}$ for MUD and MSD, respectively.

Fresh whole blood DLI, obtained by collection of small aliquots from donors, seems to be a very cost effective technique and an attractive form of immunotherapy for children. Swaminathan and cols..$^{50}$ reported their experience with early withdrawal of IS and the use of fresh whole blood DLI to mitigate relapse of leukemia and prevent graft rejection after $\mathrm{HCT}$ in children with mixed chimerism, transplanted for benign diseases or leukemia. In total, 58 patients received $\mathrm{DLI}$, in an escalating dose regimen with $\mathrm{CD}^{+}$cell/kg as follow: $1 \times 10^{5}$ (or $10^{4}$ for haploidentical recipients), $5 \times 10^{5}$ and $1 \times 10^{6}$, depending on the graft kinetics and the clinical status of the children. 
The 2-year OS and DFS were $81.1 \%$ and $67.2 \%$, respectively. The collection by phlebotomy is safe for the donors, particularly for the younger pediatric donors, who otherwise, to donate lymphocytes through apheresis machine, would need a venous catheter and volume expansion or a red blood cell pack to tolerate the procedure. This preemptive DLI escalating regimen works well for patients who requires repeated lower doses of $T$ cells.

Since monitoring MRD in Ph-positive leukemia by qRT-PCR for BCR-ABL rearrangements in marrow and blood is easy, some investigators have advocated for a MRD-triggered approach instead prophylactic. The first choice can be imatinib or dasatinib in cases with previous resistance to imatinib or presence of $A B L$ kinase domain mutations before or after $\mathrm{HCT}$, since the use of ponatinib is not approved for children yet. Patients with early molecular recurrence, within first three months after $\mathrm{HCT}$, or those with more than $10^{4}$ transcripts at any time after HCT, appear to have little benefit with imatinib, and should be started on dasatinib at 50-100 mg/day or, if intolerance, on nilotinib at 200 mg every 12 hours, with close monitoring for toxicities. ${ }^{16}$ In one prospective evaluation of 27 patients undergoing allo-HCT for $\mathrm{Ph}^{+} \mathrm{ALL}$, preemptive imatinib at MRD detection post-HCT was associated with prolonged disease-free survival in approximately half of patients, which could be anticipated by rapid achievement of molecular remission in response to therapy..$^{51} \mathrm{~A}$ phase II study, compared maintenance or preemptive MRD-triggered imatinib in $55 \mathrm{Ph}$-positive ALL patients and showed low rates of hematological relapse in both arms. Although, molecular recurrence was lower for maintenance compared with preemptive strategy. ${ }^{52}$

Some cytokines have been evaluated on their capacity to improve the efficacy of donor cells. An older approach with new interest is the combination of GM-CSF and/or interferon alpha (IFN- $a$ ) and DLI. Both cytokines increased the capacity of dendritic cells and leukemia cells to present target antigens, and improved donor T-cell stimulation by providing co-stimulatory signals and adhesion molecules. ${ }^{53}$ Cooper and cols. ${ }^{54}$ showed better disease control with the use of IFN-a to augment GVL responses, with or without DLI, in high-risk leukemia, not cured with standard transplant measures. However, they observed a high rate of GVHD (59\%) and morbidity, probably due the high dose and prolonged exposition of IFN used. They suggested that earlier IFN-a use, prompted by detection of MRD, coupled with its rapid cessation at onset of GVHD, may potentiate GVL effect and reduce mortality from GVHD in this high-risk group of children. The Chinese group put it into practice, and in consecutives, prospective clinical studies ${ }^{55-57}$, showed the safety and the efficacy of preemptive IFN- $a-2 b$ in acute leukemia and MDS pediatric and adult patients with MRD positive post-HCT. The IFN schema was 3 million units 2-3 times per week subcutaneous, for median treatment duration of 35 days (range, 4 to 180 days). The first study ${ }^{55}$ compared the preemptive use of IFN- $a$ alone to G-DLI preceded by chemotherapy and showed similar 1-year cumulative incidence of relapse, NRM and DFS (27.3\% versus $35.6 \% ; \mathrm{p}=.514)$, ( $4.5 \%$ versus $4.4 \% ; p=.985)$ and $(68.2 \%$ versus $60.0 \% ; p=.517)$, respectively. Both approaches were significantly better than those of the MRD-positive patients with IS tapering or without preemptive interventions. All patients treated with G-DLI received IS (CsA or MTX) for 2 to 6 weeks after infusion. The authors observed that, even when IFN-a treatment was discontinued, due to active GVHD, MRD remained significantly decreased and MRD-negative status was achieved, and discussed that IFN- $a$ indeed might promote the GVL effect and clear tumor cells, through enhancement of NK cell cytolytic activity as well as up-regulation of interleukin-2 (IL-2) production by T cells. In a subsequent study ${ }^{56}$, they investigated the efficacy of salvage IFN-a in 24 patients who persisted MRD-positive at 1 month after G-DLI (unsatisfactory response). IFN- $a-2 b$ started within 3 months after G-DLI, before hematological relapse, with the same schema described above, except for a reduction to 3 million units $/ \mathrm{m}^{2}$ for patients $\leq 16$ years (maximum of 3 million units) and longer treatment duration (median 80 days, range, 19-187). Most patients (75\%) achieved molecular remission, the majority of them within two months and $12.5 \%$ at $>2$ months after the start of IFN-a treatment. The 2-year DFS, OS, severe aGVHD (G-III/IV), chronic and severe cGVHD were $54.3 \%, 68.0 \%, 8.3 \%, 37.5 \%$ and $16.7 \%$, respectively.

More recently, the same group, extended the cohort of preemptive IFN- $a$ treatment to $68 \mathrm{Ph}$-negative ALL patients who had MRD positive after allo-HCT, half of them in a single bone marrow analysis (MRD $\sin +$ ) and half with consecutives MRD positive (MRDCO+), and compared the outcomes with 18 non-IFN controls. They found that patients with MRD sin+ benefit more from preemptive IFN- $a$ after allo-HCT. They stated that would be premature to derive conclusions regarding the superiority of IFN-a treatment over chemo-G-DLI for MRD positive patients. However, the outcomes were encouraging, with low incidences of NRM (6\%), severe acute (2.9\%) and cGVHD (7.5\%) and significantly higher 4-year probabilities of DFS (62\%) and OS (71\%) for IFN-a group compared 
to controls. Thus, preemptive IFN-a treatment could protect against relapse and improve long-term survival for ALL patients who had MRD after allo-HCT. ${ }^{57}$

\section{TREATMENTS OPTIONS FOR HEMATOLOGIC AND EXTRAMEDULLARY RELAPSE}

For many decades, treatment options for hematologic or extramedullary relapse (EMR) include chemotherapy, DLI, radiotherapy, second allo-HCT and often a combination between them. The landscape of strategies for relapsed/refractory leukemia has advanced a lot with the availability of molecular targeted therapies and new immunotherapies including antibody-drug conjugates, bi-specific t-cell engagers (BiTEs) and chimeric antigen receptor T (CAR-T) cells. Unfortunately, low and middle in-come countries have very limited access to these new therapies due to cost issues. For all interventions, their benefits and potential risks, particularly occurrence of severe GVHD, must be evaluate in each patient. ${ }^{9}$

The approach to post-HCT relapse has to be personalized. No simple algorithm can be adopted to address relapse after transplantation, mainly in pediatric patients. The choice of salvage therapy has to be guide by several factors, such as disease histology, donor availability, presence of targetable mutations, tumor burden, post-transplant interval, patient clinical condition, presence of active GVHD, concurrent immune suppression medications and previous treatments (response and toxicities). Standard chemotherapy can be used, combined or not with DLI or molecular target agents (bone marrow relapses) or local therapy (radiotherapy, surgery for combined or isolated extramedullary relapses). However, response rates are between 30 to $50 \%$ and toxicity can be high. If success in inducing complete or near CRs with any of the cited approaches, the question is which would be the best option: ongoing chemotherapy, DLI or inhibitor maintenance, observation, second HCT or CAR-T cell. For ALL patients with hematological relapse prophylactic intrathecal therapy (IT), usually with methotrexate, cytarabine and steroids, is recommend during chemotherapy or immunotherapy treatments.

The salvage chemotherapy for leukemia relapse before and after HCT have been change for less extended and toxic protocols. Recent comparison between FLAG and FLAG-IDA, in 76 adults and pediatric patients with relapsed and refractory acute leukemia, showed a significant higher CR rate, OS and subsequent transplant rate for FLAG regimen $(p=0.033) .{ }^{58}$ Bertaina and cols. ${ }^{59}$ evaluated bortezomib in combination with dexamethasone, doxorubicin, vincris- tine and pegylated asparaginase (VXLD) in 30 and 7 children with B-cell precursor (BCP) and T-cell ALL, respectively. Fifteen (40\%) had previous HCT and the median interval for relapse was 218 days. The CR or $\mathrm{CR}$ with incomplete platelet recovery $(\mathrm{CRp})$ rate of patients with previous allo-HCT was $60 \%$. Among the 27 patients who achieved CR/CRp, 18 underwent allo-HCT. Moreover, 12/16 patients who had failed blinatumomab responded to this combination, with 5 of them achieving MRD $<0.1 \%$. The overall 2-year OS and DFS were $31.3 \%$, but CR/CRp patients with an MRD response had a remarkable 2-year OS of $68.4 \%$. Similarly, a multicenter European study ${ }^{60}$, explored the efficacy of re-induction including bortezomib in pediatric relapsed/refractory acute lymphoblastic leukemia. Patients were randomized 1:1 to bortezo$\mathrm{mib}(1.3 \mathrm{mg} / \mathrm{m} 2 /$ dose $)$ administered early or late to a dexamethasone and vincristine backbone, with MTX intrathecal; both timing led to same results. The overall response rate (CR+PR) was $60 \%$ with a low intensity schedule, in a heavily pretreated cohort of patients.

Chemotherapy combined with DLI is a useful strategy to treat leukemia relapse following HCT. In hematological relapse, the efficacy of DLI alone varies according type and burden of the disease. Since higher doses of $\mathrm{CD}^{+}$cell would be necessary, substantial risk of severe GVHD is a limitation, mainly after unrelated or haploidentical HCT. Most patients receiving single therapeutic DLI relapse and succumb to their disease. Close monitoring of MRD and chimerism after a successful therapeutic DLI is important to identify the patients who are at high-risk of subsequent relapses. Yan and cols. ${ }^{61}$ confirmed these observations in a prospective study, including adults and pediatric patients, $66 \%$ of them underwent haplo-HCT. They concluded that MRD-guided repeated administration of chemo-G-primed-DLI protocol was effective in reducing the risk of subsequent relapse after achieving initial disease response and the utilization of short-term IS, with CsA after haplo-DLI and CsA or MTX after matched- DLI, could preserve GVL effect and either reduce the incidence of severe aGvHD.

The Acute Leukemia Working Party of European Society for Blood and Marrow Transplantation (EBMT) consensus $^{35}$ recommend cytoreductive therapy prior to haploidentical DLI for patients with a hematologic relapse after T-replete with PTCy transplants and that $1 \times 10^{6} \mathrm{CD} 3+$ cells $/ \mathrm{kg}$ is a reasonable starting dose, followed by dose escalation every 6 weeks depends on disease response and GVHD. They stated also that long-term immune tolerance after PTCy may be enough to overcome the immunological barrier of haplo-DLI and G-CSF priming may be 
not required in this setting. Besides that, since mismatched-HLA allele loss occurs in one-third of leukemia relapses after a haplo-HCT and such patients are unlikely to benefit from DLI or second HCT from original donor, this possibility must be investigate. If HLA loss confirmed, a second transplant from a related donor with a different mismatched haplotype or a mismatched unrelated donor may be considered.

Several transplant groups have been evaluated the combined chemo-DLI and chemo-second HCT strategies. ${ }^{61-71}$ Tables 1 and 2 summarizes the main ones of them.

Willasch and cols. ${ }^{62}$ reported the Frankfurt experience in a retrospective study which compared the results of 23 ALL patients relapsed post-HCT and treated with high-dose chemotherapy or specific immunotherapy (HDCHT/SIT) followed by a second HCT (transplant approach) or low-dose chemotherapy and repeated DLI (LDCHT+DLI) (non-transplant approach). The time point of relapse (until or after day +200$)$ guided the decision how to treat. Eight patients received HDCHT/SIT, followed by haploidentical HCT in 7/8. Ten received LDCHT+DLI and five palliative care. The transplant approach and non-transplant approach groups had comparable 4 -year OS of $56 \%$ and $40 \%$, respectively ( $p=0.232$ ). Prerequisites related with successful treatment of post-transplant relapse by either approaches were donor availability, good clinical condition and the capacity to achieve hematological remission by the induction treatment element. In a larger cohort study, Roux and cols..$^{63}$ aimed to compare treatment strategies in 334 consecutive children with acute leukemia relapse or progression after HCT in a 10year period. Data of 288 evaluable patients showed that the median OS duration after relapse differed according to therapy: chemo-DLI (385 days), second allograft (391 days), chemotherapy (174 days), isolated DLI (140 days) and palliative care (43 days). A second HCT or a combination of chemotherapy and DLI yielded similar outcome $(H R=0.85, p=0.53)$, unlike chemotherapy alone ( $\mathrm{HR}=1.43 \mathrm{P}=0.04)$, isolated $\mathrm{DLI}(\mathrm{HR}=1.94, \mathrm{p}<0.04)$ or palliative care $(\mathrm{HR}=4.24$, $\mathrm{p}<0.0001)$. Despite limitations of this retrospective analysis, strategies including immuno-intervention appear superior to other approaches, mostly in AML.

A multicenter Spanish study ${ }^{64}$ also reported comparable outcomes for acute leukemia (AL) relapsed patients treated with debulking therapy followed by DLI or second allo-HCT. The time interval from HCT to relapse was the only statistically significant factor with impact on outcomes, a shorter time associated lower OS and DFS. Within the DLI cohort, previous
T-cell-depleted HCT was associated with higher OS $(p=0.003)$ and DFS $(p<0.001)$ and lower $\mathrm{Cl}$ of relapse $(p=0.002)$ than T-cell-replete HCT.

Dahlberg and cols. ${ }^{65}$ helped to define subsets of pediatric patients that may have a realistic chance for long term OS with current therapies. They stated that, in contrast to ALL, it was possible to achieve DFS in patients with early AML/MDS relapse, likely due in part to better response to $\mathrm{DLI}$, which was able to bridge some AML/MDS patients to second HCT. Patients with AML/MDS also were less likely to have received a $\mathrm{TBI}$-containing regimen as conditioning for the first HCT allowing a myeloablative TBI-based second HCT regimen, which was associated with increased OS. Factors associated with improved survival included late relapse (greater than 12 months), ALL in first CR at the time of first transplant and chemotherapy-based first conditioning regimens.

The EBMT Paediatric Diseases Working Party analyzed registry data of 373 children from 120 centers with relapsed leukemia who underwent second alIo-HCT between 2004 and 2013. The 2-year OS and DFS rates were $38 \%$ and $30 \%$, while at 5 years were $29 \%$ and $25 \%$, respectively. Favorable prognostic factors for OS and LFS included $>12$ months between transplantations and occurrence of CGVHD after the first HCT (in both groups), achieve CR before the second HCT (ALL group only), and age $>12$ years (AML group only). Results were more consistent over time in the ALL group, with no significant differences between 2-year and 5-year rates of relapse, NRM, and LFS. The authors stated that relapsed acute leukemia pediatric patients have a substantial likelihood of long-term survival following second HCT. ${ }^{66}$ Similarly, Lund and cols. ${ }^{67}$ reported a 2-year LFS of 33\% after second HCT in remission compared to $19 \%$ for children and young adults with acute leukemia not in remission ( $p=0.02$ ). The corresponding 8-year probabilities were $24 \%$ and $10 \%(p=0.003)$. Late relapse led to a $10 \%$ decrement in LFS beyond the second year after second HCT. This differs from first HCT were most relapses occur within 2 years after HCT. Given the many novel targeted and immunomodulation therapies currently under development, these extended analyzes reinforce the importance of stratifying specific subgroups of patients that may benefit from a second HCT compared with those better suited to new approaches.

Despite extramedullary relapse of acute leukemia is relatively rare, with incidence ranging from 6 to $20 \%$ in single-center reports, it confers a poor prognosis, mainly if occur early post-transplant. There are no standardized therapeutic strategies for EMR af- 
ter HCT. Combination of systemic and local therapy should be considered, given that local therapy alone often results in subsequent systemic relapse. Local therapy includes surgery (mainly for gonads and soft tissues), intrathecal injection, and/or radiotherapy, and systemic therapy involves chemotherapy combined or not with target agents (e.g., dasatinib, sorafenib), immunotherapy, and, when indicated, second allo-HCT. The optimal treatment remains controversial. Responses have been reported with some monoclonal antibodies, including rituximab for B-ALL and gemtuzumab ozogamicin for AML EMR. Azacitidine and decitabine can be successfully used in the salvage treatment of AML patients who experienced EMR after allo-HCT also. It was hypothesized that HMAs are directly cytotoxic and also might increase the GVL effect by inducing leukemic cell differentiation and expression of HLA-DR to enhance the effects of DLI given concomitantly, since EMR usually do not respond well to DLI alone. ${ }^{72}$

Central nervous system (CNS) relapse in post-transplant setting, particularly for ALL patients, with prior CNS disease, pre-HCT craniospinal radiation and conditioned with $\geq 12 \mathrm{GY}$ dose of TBI plus cranial boost, is considered a challenge. Intrathecal therapy, usually with methotrexate, cytarabine and steroids, is mandatory for cerebrospinal fluid blasts clearance and maintenance, if response. However, refractory disease can happen and IT or intraventricular administration of rituximab is an option for this group of patients. Ceppi and cols. ${ }^{100}$ reported, in a multicenter intercontinental case series, 25 children with CNS involvement of CD20+ B lymphoid malignancies who received in total $163 \mathrm{IT} /$ intraventricular rituximab doses. The median number of doses received by each patient was 6 , with a median dose of $25 \mathrm{mg}$. The most common adverse events were Grades 1 and 2 peripheral neuropathies in five patients (20\%), allergy in two patients, and headache in two patients. These events were self-limited, occurring in the 48 hours after treatment and resolving within $24 \mathrm{hr}$. Three patients had more severe though transient side effects, one a grade III neuropathy and two with seizures. Eighteen patients (72\%) of those treated with IT/intraventricular rituximab, with or without other CNS directed treatment, achieved a CNS remission. The authors suggest that IT/intraventricular rituximab has therapeutic efficacy and relatively limited toxicity. Prospective trial of IT rituximab for these patients, with CNS involvement of CD20 + B lymphoid malignancies, is warranted. ${ }^{73}$ CNS relapse is less frequent in AML than in ALL patients. Patients with myeloid malignancies, who usually receive a myeloablative chemo-based regimen conditioning for HCT, may benefit of multimodal therapy that include IT therapy, chemotherapy, curative radiotherapy, sometimes DLI and maintenance with target agent if indicated. For some cases this strategy can be sufficient and second HCT can be reserved to be performed only in case of new recurrence.

\section{IMMUNOTHERAPIES AND FUTURE DIRECTIONS}

The use of immunotherapy for leukemia has been successful in providing durable remissions for heavily treated, relapsed and refractory patients who otherwise had little chance of cure. The new immunotherapies like antibody-drug conjugates, BiTEs and chimeric antigen receptor T-cells (CAR-T) cells share adverse effects such as: cytokine release syndrome (CRS) and immune effector cell-associated neurotoxicity syndrome (ICANS), which coincide with T cell activation; hypogammaglobulinemia, which can be managed by immunoglobulin administration; invasive fungal infections and venooclusive disease (VOD), particularly with inotuzumab. The BiTEs contain two antibodies, one targeting the CD3 domain of T cells and the other targeting a surface antigen on the tumor, when antibodies are bound to both targets they signal the $T$ cell to degranulate, resulting in cytotoxicity. Blinatumomab was the first BiTe, a CD3/CD19-bispecific T-cell engager, produced for B-ALL. The results of the phase I/II study and several single-institution or national retrospective evaluations showed response rates to blinatumomab ranging from $34-38 \%$ to around $60 \%$ for children with relapsed or refractory (R/R) ALL. ${ }^{74}$ Sheleghel and cols. ${ }^{75}$ reported the use of blinatumom$\mathrm{ab}$ in nine post-transplant relapsed pediatric patients with B-precursor ALL. The protocol used was a 4-week continuous IV infusion at a dosage of 5 or $15 \mu \mathrm{g} / \mathrm{m}^{2} /$ day, all patients received 18 cycles. Complete remissions were achieved by four patients after the first cycle and by 2 patients after the second cycle (with previous cytoreduction by chemotherapy), while three patients did not respond. Four patients were successfully bridge to second haplo-HCT in molecular remission. The 1-year probability of EFS was 30\%. They observed that blinatumomab could induce molecular remission and facilitate subsequent allo-HCT in posttransplant relapsed B-ALL patients with subsequent long-term LFS. The results of both phase III $\mathrm{RCTs}^{76-77}$ in children with first relapse of ALL confirm the superiority of blinatumomab in achieving MRD-negativity before HSCT and even show evidence for an advantage in OS, with less severe adverse events, mainly infections, compared to conventional chemotherapy. These results warrant the inclusion of blinatumomab into pre B-ALL relapse protocols before or after allo-HCT. Extramedullary escape and CD19 antigen loss 
are patterns of relapse following blinatumomab therapy. Interestingly, MLL1 ALL can switch to a myeloid lineage under the pressure of ALL-targeted therapies as a mechanism of resistance. ${ }^{78}$

Blinatumomab and DLI combination is a promising therapy, since blinatumomab might achieve a reduction in disease burden, and after its clearance, DLI can potentially induce GVL, which can provide longer lasting remission. Ueda and cols. ${ }^{79}$ reported four adult cases of relapsed pre-B ALL after HCT treated with concurrent blinatumomab and DLI, administered with no acute adverse effects. They kept low-dose of cyclosporine during this treatment in three patients, who achieved CR. Two of them remained in remission at 13 and 7 months of follow up after relapse, probably because they had low disease burden when the therapy started. The patient with extramedullary relapse did not respond. We found also, two case reports of concomitant use of DLI with blinatumomab following a MUD and a haploidentical HCT for mixed lineage acute leukemia ${ }^{80}$ and primary mediastinal large B-cell lymphoma ${ }^{81}$ relapsed patients, respectively.

Ongoing trials will show if blinatumomab is capable of inducing lasting remissions without a subsequent HCT and if it can be a suitable maintenance post-HCT therapy for high risk patients. Combination therapies with inotuzumab ozogamicin (InO), DLI, checkpoint inhibitors, such as PD-1- or CTLA-4-inhibitors, could enhance the efficacy of blinatumomab and are currently being test. ${ }^{82}$ Besides that, the efficacy of antibody-based immunotherapies in relapsed and refractory BCP-ALL is evident, but knowledge on their effect on CNS disease is limited. Limited efficacy in the CNS is probably due to their poor penetration into the CNS, which can, however, be overcome by IT or intraventricular application.

Inotuzumab ozogamicin, an antibody-drug conjugate designed using a monoclonal antibody directed against CD22 bound to the cytotoxic antibiotic calicheamicin. ${ }^{74}$ Data from pediatrics studies with InO for R/R-ALL, including post-HCT patients, showed that it was well tolerated and has an antileukemic effect, similarly to what observed in adults. Bhojwani and cols. ${ }^{83}$ reported a $67 \%$ CR rate in 51 pediatric patients with R/R-ALL treated with InO in a phase I study. The patients were heavily treated and $43 \%$ of them had previous HCT. However, among 21 bridged to HCT, 11 (52\%) developed sinusoidal obstructive syndrome (SOS), a higher expected rate than was previously observed in adults (11\%). The preliminary outcomes of the COG AALL1621 phase 2 trial ${ }^{84}$, which tested the efficacy of $\mathrm{InO}$ in 48 pediatric patients and young adults in second or greater relapse of B-ALL, showed CR rates $>50 \%$, nearly $33 \%$ of whom achieved MRD negativity. A more recent phase 1 study investigated the recommended phase 2 dose of $\operatorname{InO}$ in pediatric patients with multiple R/R CD22+ ALL. The dose taken forward to the ongoing phase 2 cohort of this study was $1.8 \mathrm{mg} / \mathrm{m}^{2}$ (fractionated schedule) during course 1 , as recommended in adults; the dose for subsequent courses remains at $1.5 \mathrm{mg} / \mathrm{m}^{2}$ per course up to a maximum of 6 courses, and limit of 2 cycles if $\mathrm{HCT}$ is planned. Additionally, to reduce the incidence of SOS it is recommend a longer interval between InO administration and HCT (i.e., 2 months or more), ursodiol prophylaxis and to avoid conditioning regimens with dual alkylating agents (e.g., busulfan and melphalan) and concomitant hepatotoxic drugs (e.g., azoles). ${ }^{85}$

In comparison with CAR T-cell immunotherapy, blinatumomab and InO are "off-the-shelf" and less expensive products that are easily available for use, in private health services, have been associated with a lower incidence of CRS and a quick reduction is possible in the case of adverse events, such as ICANS or CRS. Blinatumomab or InO can be effectively used to induce often-deep MRD negativity and facilitate $\mathrm{HCT}$, which has been shown to improve outcomes for many patients. Disadvantages are higher incidence of SOS with InO and lower response with blinatumomab in patients with high leukemia burden, concurrent extramedullary relapse, and the fact of all available data in R/R-ALL suggest a necessity for HCT after a bridging therapy. Further studies are necessary to help to determine at which point each therapeutic option might yield the best results. ${ }^{74}$

Several BiTEs targeting some AML-associated surface proteins (CD33, CD123, and CD371) that have shown potent experimental activities are currently undergoing clinical trials. Gemtuzumab ozogamicin (GO), a humanized anti-CD33 monoclonal antibody conjugated to the cytotoxic antibiotic agent calicheamicin, is approved for the treatment of relapsed or refractory CD33-positive AML in adults and children $\geq 2$ years old. However, GO treatment has been associated with an increased risk of hepatotoxicity and severe SOS, especially following HCT. Other non-specific serious adverse events associated with GO use are myelosuppression, bleeding/thrombocytopenia, infusion-related reaction, and tumor lysis syndrome. Fractionated dosing using $3 \mathrm{mg} / \mathrm{m} 2$ were associated with less toxicity, myelosuppression and VOD with equal efficacy. In a recent review, Cortes and cols. recommended to avoid GO in previously transplanted AML patients. ${ }^{86}$ 
The revolution in immunotherapy for hematologic neoplasms is the development of CAR-T, a targeted immunotherapy, which utilizes autologous T cells to attack malignant cells. T cells are collected through apheresis from the patient or donor and modified ex vivo, by introducing a gene that codes for an antigen recognition receptor, often a single chain variable fragment (scFv) from an antibody, which is fused to T-cell costimulatory domains. These genetically modified T-cells are transfused to the patient and the cytotoxic killing of the leukemic cells starts. ${ }^{74}$

The safety and efficacy of Tisagenlecleucel (CTL019), an anti-CD19 chimeric antigen receptor (CAR) T-cell therapy, was investigated by Maude and cols. ${ }^{87}$ in a single-center phase I/Il study involving 60 children and young adults with R/R B-cell ALL, conducted at the Children's Hospital of Philadelphia and the University of Pennsylvania showed a rate of complete remission of $93 \%$. The CRS occurred in $88 \%$ of patients and were managed with supportive measures and anti-cytokine therapy, including the interleukin-6 receptor antagonist tocilizumab. Long-term disease control without additional therapy and with persistence of tisagenlecleucel for up to 4 years were

observed in this cohort. ${ }^{88}$ Seattle Children's Hospital group published a phase I/II study ${ }^{89}$, which evaluated the efficacy of a CAR-T-cell product, transduced to express a 4-1BB costimulatory domain, in targeting CD19-positive leukemic cells, in 43 relapsed/refractory B-ALL heavily treated patients, with previous HCT in $62 \%$. The maximum tolerated dose was $10^{6}$ CART cells $/ \mathrm{kg}$. They showed a 93\% MRD-negative remission rate within 21 days, and this rate was $100 \%$ in the subset of patients who received fludarabine and cyclophosphamide lymphodepletion. The 1-year EFS of $50 \%$ and OS of $66 \%$. Reversible severe CRS and/ or reversible severe neurotoxicity occurred in 23\% of patients. Based on these studies, a global phase 2 pivotal, nonrandomized, trial (ELIANA) of tisagenlecleucel, sponsored and designed by Novartis, was performed to analyze the efficacy, safety and cellular kinetics of tisagenlecleucel. The outcomes of 75 children and young adults with R/R B-cell ALL (61\% of whom had a relapse after $\mathrm{HCT}$ ), who received an infusion of Tisacel, were published by Maude and cols. ${ }^{90}$. Within three months, the ORR was $81 \%$, with all responded patients became also MRD negative. The 6-months and 1-year EFS and OS rates were $73 \%$ and $90 \%, 50 \%$ and $76 \%$, respectively. Tisacel persistence in the blood was observed for more than one year after infusion in patients with response to treatment. CRS occurred in $77 \%$ of patients, $48 \%$ of whom received tocilizumab. Neurologic events oc- curred in $40 \%$ of patients, all managed with supportive care. Nineteen deaths occurred after tisagenlecleucel infusion, 13 (68\%) due to B-cell ALL relapse or progression; others causes were: cerebral hemorrhage due to coagulopathy and CRS (1), HHV-6-positive encephalitis due to prolonged lymphopenia (1), systemic mycosis due to prolonged neutropenia (1), unknown cause ( 1 ) and 2 deaths due to pneumonia and hepatobiliary disease each (after new therapies for ALL). The authors concluded that Tisacel produced high remission rates and durable remissions without additional therapy. The study was updated by same group ${ }^{91}$ and ORR was $82 \%$, and $62 \%$ of patients had a CR. Among patients who had CR previously, $66 \%$ were still in remission at 18 months, and the ORR was $70 \%$ at 18 months post-infusion, with a median OS not reached.

Recently, two studies analyzed the real-world clinical outcomes after Tisacel treatment. Schultz and cols. ${ }^{92}$ reported the results from Pediatric Real World CAR Consortium (PRWCC). Retrospective data collected from 15 institutions, included 185 patients infused with Tisacel. At the time of CAR T cell infusion, the median age was 12 years (range $0-26$ ). Early responses at one month and OS and EFS at 6 and 12 months are comparable to reported in ELIANA trial. The rate or CRS and ICANS was low. Comparative analysis of outcomes in patient cohorts with varying disease burden demonstrates decreasing CR, EFS, and OS in patients with high disease burden compared to patients with lower disease burden or no detectable disease at last evaluation before CAR infusion. Pasquini and cols. ${ }^{93}$ published the largest set of safety and efficacy data for tisagenlecleucel in a real-world setting, collected from a cellular therapy registry, shared to CIBMTR. This non-interventional prospective study includes 410 patients treated at 73 US centers, who had follow-up data reported (255 pediatric ALL; 155 adults NHL). Among pediatric patients with $A L L$, the initial $C R$ rate was $85.5 \%$ and the 1 -year duration of response (DOR), EFS, and OS rates were $60.9 \%, 52.4 \%$, and $77.2 \%$, respectively; all rates statistically comparable to results observed in the Eliana trial. Grade $\geq 3$ CRS and ICANS were reported in $16.1 \%$ and $9.0 \%$ of patients, respectively, compared with $48.1 \%$ and $12.7 \%$ of the ELIANA study. Pivotal Tisacel trial did not include children $<3$ years of age; while $6 \%$ of the ALL real-world cohort were age $<3$ years. Prior allo-HCT was less frequent among patients in this study than the Eliana trial ( $28 \%$ vs. $61 \%)$. Primary refractory patients were more common in the registry than in the pivotal trial (15\% vs. $8 \%)$. The authors concluded that in the real-world setting tisagenlecleucel demonstrates outcomes with similar 
efficacy and improved safety compared with those seen in the pivotal trials.

The utilization of allogeneic CAR-T cells is under experimental clinical evaluation. Zhang and cols. ${ }^{94}$ presented at the 2020 ASH Annual Meeting the results of the use of CAR-T cells derived from related donors in 37 patients (range of age: 3-61), with R/R B-ALL. Among the 37 patients, 28 relapsed following allo-HCT. For them, the lymphocytes were collected from their transplant donors (3 MSD and 25 haploidentical). For the remaining nine patients without a prior transplant, the lymphocytes were collected from a MSD $(n=5)$ or haploidentical donors $(n=$ 4). The authors showed that manufacturing CD19+ CAR-T cells derived from donors were feasible. For patients who relapse after allo-HCT, the transplant donor-derived CAR-T cells were safe and effective with a CR rate as high as $96.4 \%$, but they observed inferior efficacy of CAR T-cells derived from haploidentical donors.

Despite second generation of CD19-CAR-T have shown, in real world setting, impressive molecular responses and acceptable toxicity profile, more than half of patients will experience a relapse. Therefore, rather than using CAR-T cell therapy as a stand-alone option, consolidation with allo-HCT might increase long-term outcome. Several other targets, such as CD20 and CD22, dual-targeting CARs, combination therapy and development of allogeneic "off the shelf" therapy are under evaluation. ${ }^{95}$

Immunotherapy for T-ALL with daratumumab, a monoclonal antibody anti-CD38, and with CAR T cells targeting CD1a, CD5, and CD7 are under investigation. ${ }^{96}$ Similarly, CARs targeting CD33 and CD123 for treat AML have been tested in preclinical models ${ }^{97-98}$, however, these antigens are also expressed on normal bone marrow progenitors, raising concerns about potential bone marrow ablation. ${ }^{72}$ Clinical trials with immune-based therapeutic modalities for $A M L$, such as: monoclonal antibodies; $T$ cell engager antibodies; allo-reactive natural killer (NK) cells and CART cell; immune checkpoint blockade via blockade of PD1 (programmed cell death protein 1) and its ligand PD-L1, CTLA4 (cytotoxic T-lymphocyte associated protein 4), TIM3 (T-cell immunoglobulin and mucin domain 3) and macrophage checkpoint blockade, via CD47 with signal-regulatory protein a (CD47/SIRPa) signaling complex, are underway in adults and are expected to move to pediatric AML once safety has been well established. The ongoing clinical research continues to advance our understanding of these immune-based therapies and will help to provide guidelines for more precise clinical indications for leukemia relapsed patients. ${ }^{99,100}$

Table 3 summarizes the preventive and therapeutic interventions reviewed here according to the type of post-HCT relapse.

\section{ACKNOWLEDGMENTS}

We would like to express gratitude to Jessica Di Chiara Salgado and Simone Pereira Lermontov for the technical support in formatting the manuscript. The authors would also like to thank the inpatient and outpatient nursing and other staff of CEMO and HPP units at Rio de Janeiro and Curitiba, respectively, for their outstanding care of our patient.

Conflict of interest statement: The authors declare that there is no conflict of interest.

TABLE 1. Donor lymphocyte infusion studies including pediatric patients

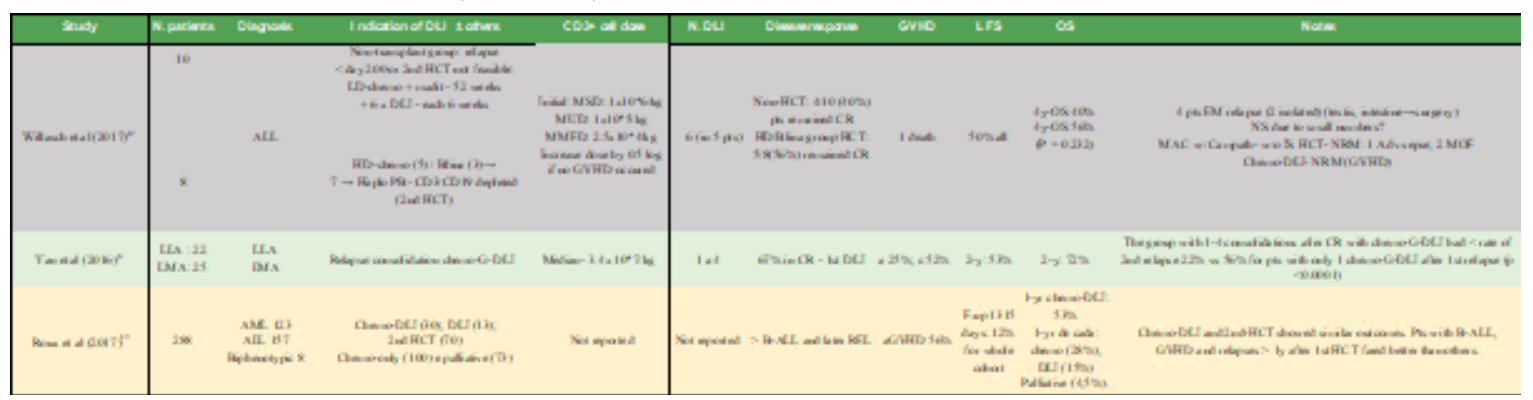

ALL: acute lymphoblastic leukemia, AML: acute myeloid leukemia, chemo-DLI: chemotherapy + Donor Lymphocyte Infusions; 2nd HCT: second Hematopoietic Cell Transplantation; LD-chemo: low-dose chemotherapy; HD-chemo: high-dose chemotherapy; MSD: matched sibling donor; MUD: matched unrelated donor; MMFD: mismatched familiar donor; PB: peripheral blood; MAC: Myeloablative conditioning; RIC: Reduced Intensity Conditioning, CR: Complete Remission,; OS: Overall Survival, LFS: leukemia free survival; aGVHD: acute graft-versus-host disease; REL: relapse; F.up: follow up; w/o IS: without immunosuppression 
TABLE 2. Second allogeneic HCT studies including pediatric patients

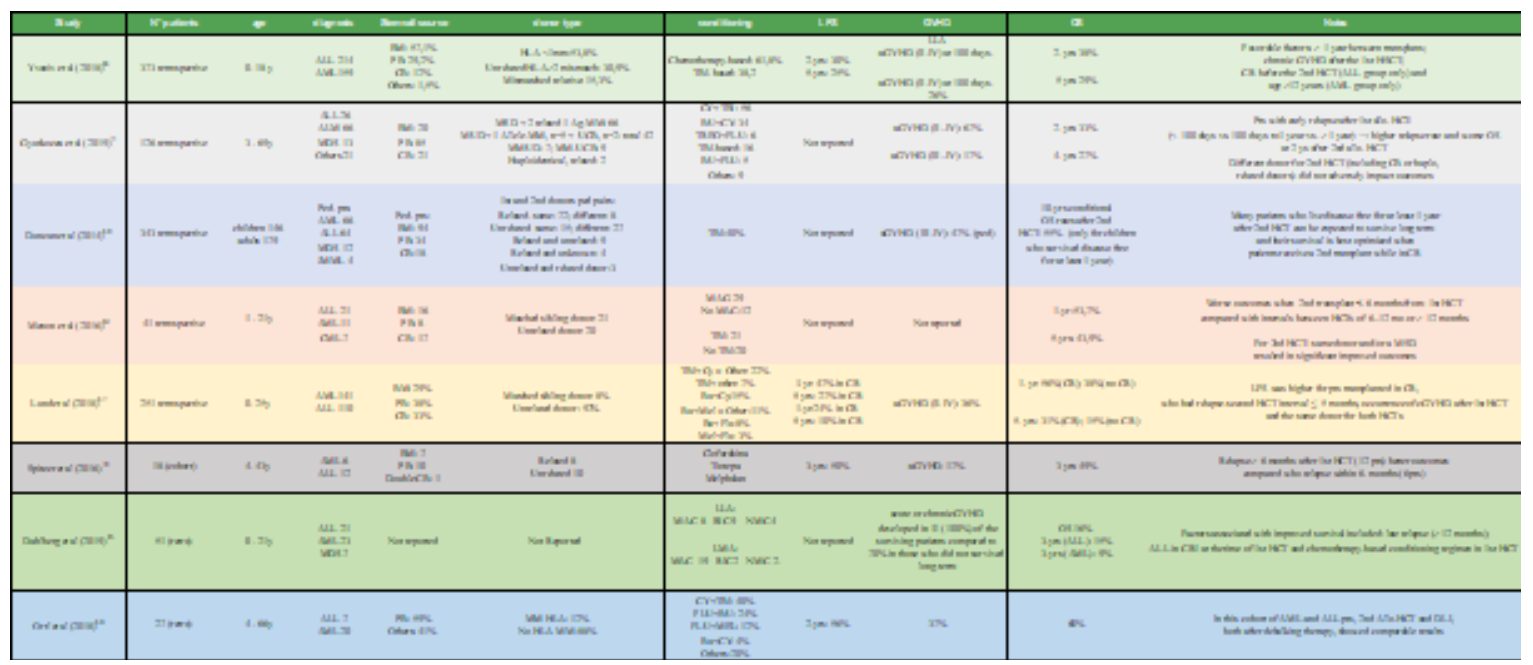

TABLE 3- Summary of preventive and therapeutic interventions for relapse post-HCT

\begin{tabular}{|c|c|c|c|c|}
\hline Interventions & Prophylactic & Preemptive & Therapeutic & $\begin{array}{c}\text { Extramedullary } \\
\text { relapse }\end{array}$ \\
\hline $\begin{array}{c}\text { Immunosuppression } \\
\text { withdrawal }\end{array}$ & yes & yes & yes & yes \\
\hline Donor lymphocyte infusion (DLI) & yes & yes & yes & no \\
\hline Chemotherapy + DLI & no & yes & yes & no \\
\hline Interferon-alpha & no & yes & yes & no \\
\hline Blinatumomab (CD19 pos ALL) & no & clinical option & yes & no \\
\hline Inotuzumab (CD22 pos ALL) & no & clinical option & yes & no \\
\hline CAR-T cell therapy & no & no & yes & no \\
\hline $\begin{array}{c}\text { Local therapy } \\
\text { Surgery and/or radiotherapy } \\
\text { intrathecal therapy }\end{array}$ & $\begin{array}{l}\text { no } \\
\text { no }\end{array}$ & $\begin{array}{l}\text { no } \\
\text { no }\end{array}$ & $\begin{array}{l}\text { no } \\
\text { yes }\end{array}$ & $\begin{array}{l}\text { yes } \\
\text { yes }\end{array}$ \\
\hline Hypomethylating agents (AML/MDS) & clinical option & yes & clinical option & no \\
\hline $\begin{array}{c}\text { Tyrosine kinase inhibitors } \\
\text { (Ph-positive acute leukemia* } \quad \text { or FLT3-ITD AML }\end{array}$ & yes & yes & yes & yes \\
\hline Chemotherapy & no & yes & yes & yes \\
\hline Second-HCT & no & no & yes & yes \\
\hline
\end{tabular}

*according mutacional status; only without active GVHD; chimeric antigen receptor T cell 


\section{REFERENCES:}

1- Locatelli F, Schrappe M, Bernardo ME, Rutella S. How I treat relapsed childhood acute lymphoblastic leukemia. Blood. 2012; 120(14):2807-16.

2- de Rooij JD, Zwaan CM, van den Heuvel-Eibrink M. Pediatric AML: From Biology to Clinical Management. J Clin Med. 2015; 4(1):127-49.

3- Seber A, Gomes A, Vieira AK, Rodrigues ALM, Silva AMM, Zanette A, et al. HSCT for Pediatric Diseases. JBMTCT.2021; 4(1):138-146

4 - D'Souza A, Fretham C, Lee SJ, Arora M, Brunner J, Chhabra S, et al. Current Use of and Trends in Hematopoietic Cell Transplantation in the United States. Biol Blood Marrow Transplant.2020; 26(8):e177-e182.

5- Levinson A, Arnold S, Jin Z, Bhatia M, Geroge D, Garvin $\mathrm{JH}$, et al. Timing and Utility of Relapse Surveillance after Allogeneic Hematopoietic Cell Transplantation in Children with Leukemia. Biol Blood Marrow Transplant. 2017;23(4):696-700.

6- Bader P, Salzmann-Manrique E, Balduzzi A, Dalle $\mathrm{JH}$, Woolfrey $\mathrm{AE}$, Bar M, et al. More precisely defining risk peri-HCT in pediatric ALL: pre- vs post-MRD measures, serial positivity, and risk modeling. Blood Adv. 2019; 3(21):3393-3405.

7- Tavares RCB, Bonfim CS, Seber A, Lermontov SP, Coulturato V, Zecchin VG, et al. Hematopoietic cell transplantation in pediatric patients with acute leukemias or myelodysplastic syndrome using unrelated adult or umbilical cord blood donors in Brazil. Pediatr Transplant. 2020; 24(7): e13789.

8- de Melo Rodrigues AL, Bonfim C, Seber A, Coulturato VAR, Zecchin VG, Nichele $S$, et al. Allogeneic Hematopoietic Stem Cell Transplantation for Children and Adolescents with Acute Myeloid Leukemia in Brazil: A Multicentric Retrospective Study. Cell Transplant. 2020; 29:963689720949175.

9- Pulsipher MA, Langholz B, Wall DA, Schultz KR, Bunin N, Carrol W, et al. Risk factors and timing of relapse after allogeneic transplantation in pediatric ALL: for whom and when should interventions be tested? Bone Marrow Transplant. 2015; 50(9):1173-9.

10- Zeiser R, Beelen DW, Bethge W, Bornhäuser M, Bug G, Burchert A, et al. Biology-Driven Approaches to Prevent and Treat Relapse of My- eloid Neoplasia after Allogeneic Hematopoietic Stem Cell Transplantation. Biol Blood Marrow Transplant. 2019;25(4):e128-e140.

11- Molina B, Gonzalez Vicent M, Herrero B, Deltoro $\mathrm{N}$, Ruiz J, Martinez AP, et al. Kinetics and Risk Factors of Relapse after Allogeneic Stem Cell Transplantation in Children with Leukemia: A LongTerm Follow-Up Single-Center Study. Biol Blood Marrow Transplant. 2019; 25(1):100-106.

12- Inaba $\mathrm{H}$, Pui $\mathrm{CH}$. Advances in the Diagnosis and Treatment of Pediatric Acute Lymphoblastic Leukemia. J Clin Med. 2021;10(9):1926.

13- Weiss M, Steinbach D, Zintl F, Beck J, Gruhn B. Superior outcome using cyclosporin $A$ alone versus cyclosporin $A$ plus methotrexate for post-transplant immunosuppression in children with acute leukemia undergoing sibling hematopoietic stem cell transplantation. J Cancer Res Clin Oncol. 2015;141(6):1089-94.

14- Chen H, Liu KY, Xu LP, Liu DH, Chen YH, Zha$\mathrm{OXY}$, et al. Administration of imatinib after allogeneic hematopoietic stem cell transplantation may improve disease-free survival for patients with Philadelphia chromosome-positive acute lymphoblastic leukemia. J Hematol Oncol. 2012; 5:29.

15- Biondi A, Gandemer V, De Lorenzo P, Cario G, Campbell M, Castor A, et al. Imatinib treatment of paediatric Philadelphia chromosome-positive acute lymphoblastic leukemia (EsPhALL2010): a prospective, intergroup, open-label, single-arm clinical trial. Lancet Haematol. 2018; 5(12):e641-e652

16- Giebel S, Czyz A, Ottmann O, Baron F, Brissot E, Ciceri $F$, et al. Use of tyrosine kinase inhibitors to prevent relapse after allogeneic hematopoietic stem cell transplantation for patients with Philadelphia chromosome-positive acute lymphoblastic leukemia: A position statement of the Acute Leukemia Working Party of the European Society for Blood and Marrow Transplantation. Cancer. 2016; 122(19):2941-51

17- Warraich Z, Tenneti P, Thai T, Hubben A, Amin $\mathrm{H}$, McBride $A$, et al. Relapse Prevention with Tyrosine Kinase Inhibitors after Allogeneic Transplantation for Philadelphia Chromosome-Positive Acute Lymphoblast Leukemia: A Systematic Review. Biol Blood Marrow Transplant. 2020; 26(3):e55-e64. 
18- Watanabe A, Chansu S, Ogawa A, Asami K, Imamura M. Prophylactic post-transplant dasatinib administration in a pediatric patient with Philadelphia chromosome-positive acute lymphoblastic leukemia. Pediatr Int. 2013; 55(3):e56-8.

19- Shen S, Chen X, Cai J, Yu J, Gao J, Hu S, et al. Effect of Dasatinib vs Imatinib in the Treatment of Pediatric Philadelphia Chromosome-Positive Acute Lymphoblastic Leukemia: A Randomized Clinical Trial. JAMA Oncol. 2020 Mar 1;6(3):358366.

20- Aldoss I, Gaal K, Al Malki MM, Ali H, Nakamura $\mathrm{R}$, Forman SJ, et al. Dasatinib-Induced Colitis after Allogeneic Stem Cell Transplantation for Philadelphia Chromosome-Positive Acute Lymphoblastic Leukemia. Biol Blood Marrow Transplant. 2016; 22(10):1900-1903.

21- Gagelmann N, Wolschke C, Klyuchnikov E, Christopeit M, Ayuk F, Kroger N. TKI Maintenance After Stem-Cell Transplantation for FLT3ITD Positive Acute Myeloid Leukemia: A Systematic Review and Meta-Analysis. Front Immunol. 2021;12:630429.

22- Tarlock K, Chang B, Cooper T, Gross T, Gupta S, Neudorf $S$ et al. Sorafenib treatment following hematopoietic stem cell transplant in pediatric FLT3/ITD acute myeloid leukemia. Pediatr Blood Cancer. 2015;62(6):1048-54.

23- Xuan L, Wang $Y$, Huang $F$, Jiang $E$, Deng $L$, Wu $B$, et al. Effect of sorafenib on the outcomes of patients with FLT3-ITD acute myeloid leukemia undergoing allogeneic hematopoietic stem cell transplantation. Cancer. 2018;124:1954- 63.

24-Shi J, Cao L, Luo Y, Zhao Y, Tan Y, Yu J, et al. Maintenance sorafenib is superior to prophylactic donor lymphocyte infusion at improving the prognosis of acute myeloid leukemia with FMS-like tyrosine kinase 3 internal tandem duplication after allogeneic hematopoietic stem cell transplantation. Bone Marrow Transplant. (2020) 56:293-6.

25- Soiffer RJ, Chen YB. Pharmacologic agents to prevent and treat relapse after allogeneic hematopoietic cell transplantation. Blood Adv. 2017 Nov 28;1(25):2473-2482.

26- de Lima M, Giralt S, Thall PF, Silva LP, Jones RB, Komanduri $\mathrm{K}$, et al. Maintenance therapy with low-dose azacitidine after allogeneic hematopoietic stem cell transplantation for recurrent acute myelogenous leukemia or myelodys- plastic syndrome: a dose and schedule finding study. Cancer. 2010;116(23):5420-5431.

27-Oran B, de Lima M, Garcia-Manero G,Thall PF, Lin $R$, Popat $U$, et al. A phase 3 randomized study of 5 -azacitidine maintenance vs observation after transplant in high-risk AML and MDS patients. Blood Adv. 2020; 4(21):5580-5588.

28- Tamura A, Ishida T, Saito A, Yamamoto N, Yokoi $T$, Uemura $S$, et al. Low-dose azacitidine maintenance therapy after allogeneic stem cell transplantation for high-risk pediatric acute myeloid leukemia. Pediatr Blood Cancer. 2018; 65(10):e27284.

29- Oshrine BR, Shyr D, Hale G, Petrovic A. Lowdose azacitidine for relapse prevention after allogeneic hematopoietic cell transplantation in children with myeloid malignancies. Pediatr Transplant. 2019; 23(4):e13423.

30- Huschart E, Miller H, Salzberg D, Campbell C, Beebe K, Schwalbach C, et al. Azacitidine and prophylactic donor lymphocyte infusions after hematopoietic stem cell transplantation for pediatric high-risk acute myeloid leukemia. Pediatr Hematol Oncol. 2021;38(2):154-160.

31- Patriarca F, Sperotto A, Lorentino F, Oldani E, Mammoliti $S$, Isola $M$, et al. Donor Lymphocyte Infusions After Allogeneic Stem Cell Transplantation in Acute Leukemia: A Survey From the Gruppo Italiano Trapianto Midollo Osseo (GITMO). Front Oncol. 2020; 10:572918.

32- Hasskarl J, Zerweck A, Wäsch R, llhorst G, Bertz $\mathrm{H}$, Finke J. Induction of graft versus malignancy effect after unrelated allogeneic PBSCT using donor lymphocyte infusions derived from frozen aliquots of the original graft. Bone Marrow Transplant. 2012;47(2):277-82.

33- Schneidawind C, Jahnke S, Schober-Melms I, Schumm M, Handgretinger R, Faul $C$, et al. G-CSF administration prior to donor lymphocyte apheresis promotes anti-leukaemic effects in allogeneic HCT patients. Br J Haematol. 2019;186(1):60-71.

34- Yan CH, Liu QF, Wu DP, Zhang X, Xu LP, Zhang $\mathrm{XH}$ et al. Prophylactic Donor Lymphocyte Infusion (DLI) Followed by Minimal Residual Disease and Graft-versus-Host Disease-Guided Multiple DLIs Could Improve Outcomes after Allogeneic Hematopoietic Stem Cell Transplantation in Patients with Refractory/Relapsed Acute Leukemia. Biol Blood Marrow Transplant.2017; 
23(8):1311-1319. Erratum in: Biol Blood Marrow Transplant. 2020; 26(1):214.

35- Dholaria B, Savani BN, Labopin M, Luznik L, Ruggeri $A$, Mielke $S$, et al. Clinical applications of donor lymphocyte infusion from an HLA-haploidentical donor: consensus recommendations from the Acute Leukemia Working Party of the EBMT. Haematologica. 2020;105(1):47-58.

36- Gilman AL, Leung W, Cowan MJ, Cannon M, Epstein S, Barnhart C, et al. Donor lymphocyte infusion and methotrexate for immune recovery after T-cell depleted haploidentical transplantation. Am J Hematol. 2018; 93(2):169-178.

37- Jaiswal SR, Zaman S, Chakrabarti A, Sen S, Mukherjee $S$, Bhargava $S$, et al. Improved Outcome of Refractory/ Relapsed Acute Myeloid Leukemia after Post-Transplantation Cyclophosphamide-Based Haploidentical Transplantation with Myeloablative Conditioning and Early Prophylactic Granulocyte-Colony-Stimulating Factor-Mobilized Donor Lymphocyte Infusions. Biol Blood Marrow Transplant. 2016;22(10):18671873.

38- Berry DA, Zhou S, Higley H, Mukundan L, Fu S, Reaman GH, et al. Association of Minimal Residual Disease With Clinical Outcome in Pediatric and Adult Acute Lymphoblastic Leukemia: A Meta-analysis. JAMA Oncol. 2017; 3(7):e170580.

39- Ngai LL, Kelder A, Janssen JJWM, Ossenkoppele GJ, Cloos J. MRD Tailored Therapy in AML: What We Have Learned So Far. Front Oncol. 2021;10:603636

40- Bader P, Niethammer D, Willasch A, Kreyenberg $\mathrm{H}$, Klingebiel T. How and when should we monitor chimerism after allogeneic stem cell transplantation? Bone Marrow Transplant.2005; 35(2):107-119.

41- Delie A, Verlinden A, Beel K, Deeren D, Mazure $D$, Baron $F$, et al. Use of chimerism analysis after allogeneic stem cell transplantation: Belgian guidelines and review of the current literature. Acta Clin Belg.2020; 2:1-9.

42- Chen CT, Gau JP, Liu JH, Chiou TJ, Hsiao LT, Liu YC. Early achievement of full donor chimerism after allogeneic hematopoietic stem cell transplantation predicts lower relapse risk in patients with acute lymphoblastic leukemia. J Chin Med Assoc.2018; 81(12):1038-1043.

43- Broglie L, Helenowski I, Jennings LJ, Schafernak k, Duers R, Schneidermann J, et al. Early mixed T-cell chimerism is predictive of pediatric AML or MDS relapse after hematopoietic stem cell transplant. Pediatr Blood Cancer.2017; 64(9).

44- Solomon SR, Sizemore CA, Zhang X, Brown S, Holland HK, Morris LE, et al. Preemptive DLI without withdrawal of immunosuppression to promote complete donor T-cell chimerism results in favorable outcomes for high-risk older recipients of alemtuzumab-containing reduced-intensity unrelated donor allogeneic transplant: a prospective phase II trial. Bone Marrow Transplant. 2014; 49(5):616-21.

45- Caldemeyer LE, Akard LP, Edwards JR, Tandra A, Wagenknecht DR, Dugan MJ. Donor lymphocyte infusions used to treat mixed-chimeric and high-risk patient populations in the relapsed and nonrelapsed settings after allogeneic transplantation for hematologic malignancies are associated with high five-year survival if persistent full donor chimerism is obtained or maintained. Biol Blood Marrow Transplant.2017; 23(11):1989-1997.

46- Rettinger $E$, Willasch $A M$, Kreyenberg $H$, Borkhardt A, Holter W, Kremens B et al. Preemptive immunotherapy in childhood acute myeloid leukemia for patients showing evidence of mixed chimerism after allogeneic stem cell transplantation. Blood. 2011; 118(20):5681-8.

47- Beck JF, Klingebiel $T$, Kreyenberg $H$, Schaudt A, Wolle W, Niethammer D, Bader P. Relapse of childhood ALL, AML and MDS after allogeneic stem cell transplantation can be prevented by donor lymphocyte infusion in a critical stage of increasing mixed chimerism. Klin Padiatr. 2002; 214(4):201-5.

48- Rujkijyanont $P$, Morris C, Kang G, Hartford C, Triplett B, Dallas $M$, et al. Risk-adapted donor lymphocyte infusion based on chimerism and donor source in pediatric leukemia. Blood Cancer J. 2013; 30(3):e137.

49- Horn B, Wahlstrom JT, Melton A, Liou A, Ouachee-Chardin M, Sunkersett G, et al. Early mixed chimerism-based preemptive immunotherapy in children undergoing allogeneic hematopoietic stem cell transplantation for acute leukemia. Pediatr Blood Cancer.2017; 64(8).

50- Swaminathan VV, Uppuluri R, Patel S, Sivashankaran M, Ravichandran N, Ramanan KM, et al. Safety and efficacy of fresh whole blood donor 
lymphocyte infusion in children. Bone Marrow Transplant. 2019; 54(11):1892-1897.

51- Wassmann B, Pfeifer $H$, Stadler M, Bornhaüser M, Bug G, Scheuring UJ, et al. Early molecular response to posttransplantation imatinib determines outcome in MRD+ Philadelphia-positive acute lymphoblastic leukemia (Ph+ ALL). Blood. 2005;106(2):458-463.

52- Pfeifer H, Wassmann B, Bethge W, Dengler J, Bornhauser M, StadlerM, et al. ; GMALL Study Group. Randomized comparison of prophylactic and minimal residual disease-triggered imatinib after allogeneic stem cell transplantation for BCR-ABL1-positive acute lymphoblastic leukemia. Leukemia. 2013;27(6):1254-1262.

53- de Lima M, Porter DL, Battiwalla M, Bishop MR, Giralt SA, Hardy NM, et al. Proceedings from the National Cancer Institute's Second International Workshop on the Biology, Prevention, and Treatment of Relapse After Hematopoietic Stem Cell Transplantation: part III. Prevention and treatment of relapse after allogeneic transplantation. Biol Blood Marrow Transplant. 2014; 20(1):4-13.

54- Cooper N, Rao K, Goulden N, Amrolia P, Veys P. Alpha interferon augments the graft-versus-leukaemia effect of second stem cell transplants and donor lymphocyte infusions in high-risk paediatric leukaemias. Br J Haematol. 2012;156(4):550-552.

55- Mo XD, Zhang $\mathrm{XH}$, Xu LP, Wang $\mathrm{Y}$, Yan $\mathrm{CH}$, Chen $\mathrm{H}$, et al. Interferon-a: A Potentially Effective Treatment for Minimal Residual Disease in Acute Leukemia/Myelodysplastic Syndrome after Allogeneic Hematopoietic Stem Cell Transplantation. Biol Blood Marrow Transplant. 2015; 21(11):1939-47.

56- Mo X, Zhang X, Xu L, Wang Y, Yah C, Chen H, et al. Interferon-a salvage treatment is effective for patients with acute leukemia / myelodysplastic syndrome with unsatisfactory response to minimal residual disease-directed donor lymphocyte infusion after allogeneic hematopoietic stem cell transplantation. Front Med. 2019; 13(2):238-249.

57- Liu S, Luo X, Zhang X, Xu L, Wang Y, Yan C, et al. Preemptive interferon-a treatment could protect against relapse and improve long-term survival of ALL patients after allo-HSCT. Sci Rep. 2020;10(1):20148.

58- Farooq MU, Mushtaq F, Farooq A, Khan DH, Mir
MA. FLAG vs FLAG-IDA: outcomes in relapsed/ refractory acute leukemias. Cancer Chemother Pharmacol. 2019; 83(6):1191-1193.

59- Bertaina A, Vinti L, Strocchio L, Gaspari S, Caruso $\mathrm{R}$, Algeri $\mathrm{M}$, et al. The combination of bortezomib with chemotherapy to treat relapsed/ refractory acute lymphoblastic leukaemia of childhood. Br J Haematol. 2017; 176(4):629-636.

60- Kaspers GJL, Niewerth D, Wilhelm BAJ, Houtem PS, Lopez-Yurda M, Berkhof J, et al. An effective modestly intensive re-induction regimen with bortezomib in relapsed or refractory paediatric acute lymphoblastic leukaemia. Br J Haematol. 2018;181(4):523-527.

61- Yan $\mathrm{CH}$, Wang Y, Wang JZ, Chen YH, Chen Y, Wang $F$, et al. Minimal residual disease- and graft-vs.-host disease-guided multiple consolidation chemotherapy and donor lymphocyte infusion prevent second acute leukemia relapse after allotransplant. J Hematol Oncol. 2016; 9(1):87.

62- Willasch AM, Salzmann-Manrique E, Krenn T, Duerken M, Faber J, Opper J, et al. Treatment of relapse after allogeneic stem cell transplantation in children and adolescents with ALL: the Frankfurt experience. Bone Marrow Transplant.2017; 52(2):201-208.

63- Roux C, Tifratene K, Socié G, Galabrum C, Bertrand $Y$, Rialland $F$, et al. Outcome after failure of allogeneic hematopoietic stem cell transplantation in children with acute leukemia: a study by the société Francophone de greffe de moelle et de thérapie cellulaire (SFGM-TC). Bone Marrow Transplant. 2017; 52(5):678-682.

64- Ortí G, Sanz J, García-Cadenas I, Sanchez-Ortega I, Alonso L, Jimenez MJ, et al. Analysis of relapse after transplantation in acute leukemia: $\mathrm{A}$ comparative on second allogeneic hematopoietic cell transplantation and donor lymphocyte infusions. Exp Hematol. 2018; 62:24-32.

65- Dahlberg A, Leisenring W, Bleakley M, Meshinchi S, Baker KS, Summers C, et al. Prognosis of relapse after hematopoietic cell transplant (HCT) for treatment of leukemia or myelodysplastic syndrome (MDS) in children. Bone Marrow Transplant. 2019; 54(8):1337-1345.

66- Yaniv I, Krauss AC, Beohou E, Dalissier A, Corbacioglu S, Zecca M, et al. Second Hematopoietic Stem Cell Transplantation for Post-Transplantation Relapsed Acute Leukemia in Children: A 
Retrospective EBMT-PDWP Study. Biol Blood Marrow Transplant. 2018; 24(8):1629-1642.

67- Lund TC, Ahn KW, Tecca HR, Hilgers MV, Abdel-Azim $\mathrm{H}$, Abraham $\mathrm{A}$, et al. Outcomes after Second Hematopoietic Cell Transplantation in Children and Young Adults with Relapsed Acute Leukemia. Biol Blood Marrow Transplant. 2019; 25(2):301-306.

68- Duncan CN, Majhail NS, Brazauskas R, Wang Z, Cahn JY, Gragoul HA, et al. Long-term survival and late effects among one-year survivors of second allogeneic hematopoietic cell transplantation for relapsed acute leukemia and myelodysplastic syndromes. Biol Blood Marrow Transplant. 2015; 21(1):151-8.

69- Menon NN, Jenkins LM, Cui H, Jenkins C, Answer $F$, Yeager $A$, et al. Factors associated with improved outcomes after second allogeneic hematopoietic cell transplantation for relapsed pediatric leukemia. Ann Hematol. 2016; 95(4):637-44.

70- Spitzer B, Perales MA, Kernan NA, Prockop SE, Zabor EC, Webb N, et al. Second Allogeneic Stem Cell Transplantation for Acute Leukemia Using a Chemotherapy-Only Cytoreduction with Clofarabine, Melphalan, and Thiotepa. Biol Blood Marrow Transplant. 2016; 22(8):1449-1454.

71- Gyurkocza B, Storb R, Chauncey TR, Maloney DG, Storer B, Sandmaier BM. Second allogeneic hematopoietic cell transplantation for relapse after first allografts. Leuk Lymphoma. 2019; 60(7):1758-1766.

72- Ge L, Ye F, Mao X, Chen J, Sun A, Zhu X et al. Extramedullary relapse of acute leukemia after allogeneic hematopoietic stem cell transplantation: different characteristics between acute myelogenous leukemia and acute lymphoblastic leukemia. Biol Blood Marrow Transplant. 2014; (7):1040-7.

73- Ceppi F, Weitzman S, Woessmann W, Davies K, Lassaletta A, Reismuller B, et al. Safety and efficacy of intrathecal rituximab in children with $B$ cell lymphoid CD20+ malignancies: An international retrospective study. Am J Hematol. 2016; 91(5):486-491.

74- Foster JB, Maude SL. New developments in immunotherapy for pediatric leukemia. Curr Opin Pediatr. 2018; 30:25-29.

75-Schlegel P, Lang P, Zugmaier G, Ebinger M, Kreyenberg $H$, Witte KE, et al. Pediatric posttrans- plant relapsed/refractory B-precursor acute lymphoblastic leukemia shows durable remission by therapy with the T-cell engaging bispecific antibody blinatumomab. Haematologica. 2014; 99(7):1212-9.

76- Brown PA, Ji L, Xu X, Devidas M, Hogan LE, Borowitz MJ, et al. Effect of Post-reinduction Therapy Consolidation With Blinatumomab vs Chemotherapy on Disease-Free Survival in Children, Adolescents, and Young Adults With First Relapse of B-Cell Acute Lymphoblastic Leukemia: A Randomized Clinical Trial. JAMA. 2021; 325(9):833-842.

77-Locatelli F, Zugmaier G, Rizzari C, Morris JD, Gruhn $B$, Klingebiel T, et al. Effect of Blinatumomab vs Chemotherapy on Event-Free Survival Among Children With High-risk First-Relapse B-Cell Acute Lymphoblastic Leukemia: A Randomized Clinical Trial. JAMA. 2021; 325(9):843-854.

78- Aldoss I, Song J, Stiller T, Nguyen T, Palmer J, O'Donnell $\mathrm{M}$, et al. Correlates of resistance and relapse during blinatumomab therapy for relapsed/refractory acute lymphoblastic leukemia. Am J Hematol. 2017; 92(9):858-865.

79- Ueda M, de Lima M, Caimi P, Tomlinson B, Little $\mathrm{J}$, Creger R, et al. Concurrent blinatumomab and donor lymphocyte infusions for treatment of relapsed pre-B-cell ALL after allogeneic hematopoietic cell transplant. Bone Marrow Transplant. 2016; 51(9):1253-5.

80- Durer S, Durer C, Shafqat M, Comba IY, Malik $\mathrm{S}$, Faridi $\mathrm{W}$, et al. Concomitant use of blinatumomab and donor lymphocyte infusion for mixed-phenotype acute leukemia: a case report with literature review. Immunotherapy. 2019; 11(5):373-378.

81- Smith J, Kumar A, Stanton NA, Katsanis E. Concurrent application of blinatumomab and haploidentical donor leukocyte infusions for refractory primary mediastinal large B-cell lymphoma. Ther Adv Hematol. 2021; 12:2040620721994348.

82- Queudeville M, Ebinger M. Blinatumomab in Pediatric Acute Lymphoblastic Leukemia-From Salvage to First Line Therapy (A Systematic Review). J Clin Med. 2021;10(12):2544

83- Bhojwani D, Sposto R, Shah NN, Rodriguez V, Yun C, Stetler-Stevenson M, et al. Inotuzumab ozogamicin in pediatric patients with relapsed/ refractory acute lymphoblastic leukemia. Leukemia. 2019;33(4):884-892. 
84- O'Brien MM, Ji L, Shah NN, Rheungold SR, Bhojwani D, Yi JS, et al. A phase 2 trial of inotuzumab ozogamicin (InO) in children and young adults with relapsed or refractory $(R / R) C D 22+B$-acute lymphoblastic leukemia (B-ALL): results from Children's Oncology Group Protocol AALL1621. Blood. 2019; 134(Supplement 1):741-741.

85- Brivio E, Locatelli F, Lopez-Yurda M, Malone A, Diaz-de-Heredia C, Bielorai B, Rossig C, et al. A phase 1 study of inotuzumab ozogamicin in pediatric relapsed/refractory acute lymphoblastic leukemia (ITCC-059 study). Blood. 2021;137(12):1582-1590.

86- Cortes JE, de Lima M, Dombret H, Estey EH, Giralt SA, Montesinos $\mathrm{P}$, et al. Prevention, recognition, and management of adverse events associated with gemtuzumab ozogamicin use in acute myeloid leukemia. J Hematol Oncol. 2020; 13(1):137.

87- Maude SL, Teachey DT, Rheingold SR, Shaw PA, Aplenc R, Barrett DM, et al. Sustained remissions with CD19-specific chimeric antigen receptor (CAR)-modified T cells in children with relapsed/refractory ALL. J Clin Oncol. 2016; 34(Suppl 15):3011.

88- Grupp SA, Maude SL, Shaw PA, Aplenc R, Barret DM, Barker CS, et al. Durable remissions in children with relapsed/refractory ALL treated with $T$ cells engineered with a CD19-targeted chimeric antigen receptor (CTL019). Blood. 2015; 126:681.

89- Gardner RA, Finney O, Annesley C, Brakke H, Summers $C$, Leger $K$, et al. Intent-to-treat leukemia remission by CD19 CAR T cells of defined formulation and dose in children and young adults. Blood 2017; 129:3322-3331.

90- Maude SL, Laetsch TW, Buechner J, Boyer M, Bittercourt $\mathrm{H}$, Bader $\mathrm{P}$, et al. Tisagenlecleucel in Children and Young Adults with B-Cell Lymphoblastic Leukemia. N. Engl. J. Med. 2018, 378:439448.

91- Grupp SA, Maude SL, Rives S, Baruchel A, Boyer MW, Bittencourt $\mathrm{H}$, et al. Updated Analysis of the Efficacy and Safety of Tisagenlecleucel in Pediatric and Young Adult Patients with Relapsed/ Refractory ( $r / r)$ Acute Lymphoblastic Leukemia. Blood 2018, 132 (Suppl. 1), 895.
92- Schultz L, Baggott C, Prabhu S, Paccenta H, Phillips $C L$, Rossoff J, et al. Disease Burden Impacts Outcomes in Pediatric and Young Adult B-Cell Acute Lymphoblastic Leukemia after Commercial Tisagenlecleucel: Results from Pediatric Real World CAR Consortium (PRWCC). Blood 2020, $136,14-15$.

93- Pasquini MC, Hu ZH, Curran K, Laetschet T, Locke F, Rouce R, al. Real-world evidence of tisagenlecleucel for pediatric acute lymphoblastic leukemia and non-Hodgkin lymphoma. Blood Adv. 2020, 4, 5414-5424.

94- Zhang X, Yang J, Li W, Zhang G, Li J, Song L, et al. Feasibility, and Efficacy of Donor-Derived cd19-Targeted Car t-Cell Therapy in Refractory/Relapsed(r/r)b-Cell Acute Lymphoblastic Leukemia (b-all) Patients. Blood. 2020, 136 (Suppl.1), 4-6.

95- Martino M, Alati C, Canale FA, Musuraca G, Martinelli G, Chercione C. A Review of Clinical Outcomes of CAR T-Cell Therapies for B-Acute Lymphoblastic Leukemia. Int J Mol Sci. 2021;22(4):2150.

96- Pui $\mathrm{CH}$. Precision medicine in acute lymphoblastic leukemia. Front Med. 2020; 14(6):689700.

97- Kim MY, Yu KR, Kenderian SS, Ruella M, Chen S, Shin TH, et al. Genetic inactivation of CD33 in hematopoietic stem cells to enable CAR T cell immunotherapy for acute myeloid leukemia. Cell. (2018) 173:1439-53.

98- Borot F, Wang H, Ma Y, Jafarov T, Raza A, Ali AM, et al. Gene-edited stem cells enable CD33-directed immune therapy for myeloid malignancies. Proc Natl Acad Sci USA. (2019) 116:1197887.

99- Isidori A, Cerchione C, Daver N, DiNardo C, Garcia-Manero G, Konopleva M, et al. Immunotherapy in Acute Myeloid Leukemia: Where We Stand. Front Oncol. 2021; 11:656218.

100- Ghosh A, Barba P, Perales MA. Checkpoint inhibitors in AML: are we there yet? Br J Haematol. 2020;188(1):159-167. 